\title{
Por uma ética da desnaturalização: A nudez no teatro de Marcio Abreu
}

Towards an ethics of denaturalization: Nudity in the theatre of Marcio Abreu

\section{Daniele Avila Small}

Daniele Avila Small

Doutoranda em Artes Cênicas pela

Universidade Federal do Estado do Rio de Janeiro (Unirio)

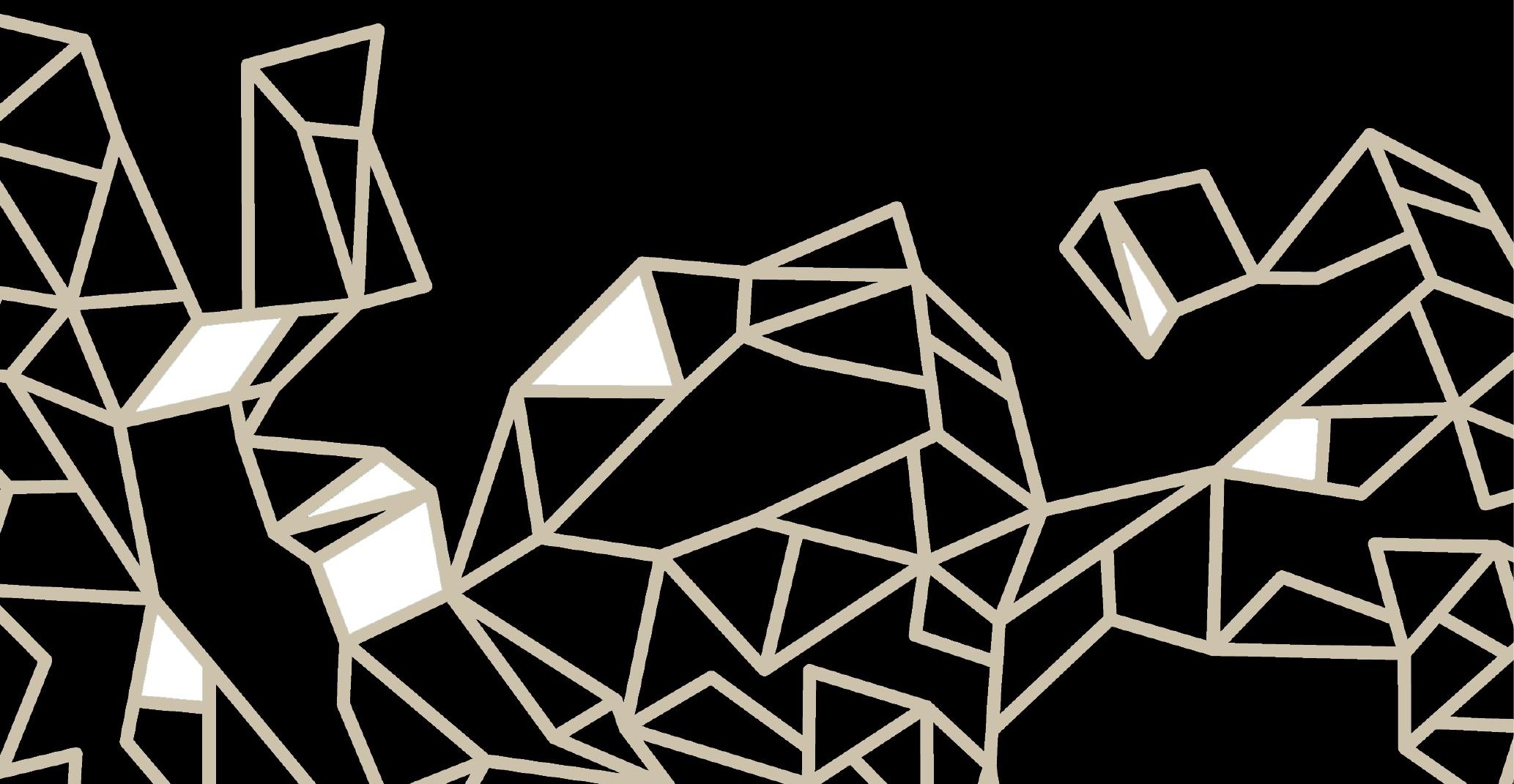




\section{Resumo}

Este ensaio pretende investigar a nudez no teatro de Marcio Abreu e da companhia brasileira de teatro como estratégia crítica para desestabilizar comportamentos naturalizados no teatro. As peças Descartes com lentes, Isso te interessa?, PROJETO bRASIL e Nós serão brevemente abordadas como exemplos em que a nudez aparece como artifício de elaboração formal que pode convocar o corpo do espectador à presença e à atenção e sua mente a elaborar sobre as coisas do teatro e sobre as coisas do mundo.

Palavras-chave: Marcio Abreu, Companhia Brasileira de Teatro, Nudez, Pacto de ausência, Literalidade.

\section{Abstract.}

This paper intends to investigate nudity in the theatre of Marcio Abreu and companhia brasileira de teatro as a critical strategy to destabilize naturalized behaviors in the theatre. Four plays - Descartes com lentes, Isso te interessa?, PROJETO bRASIL and Nós - will be briefly analyzed as examples of how nudity is used as an artifice of formal elaboration which may summon the spectator's body to an estate of presence and attention and summon their mind to elaborate on theatre and consequently on the world.

Keywords: Marcio Abreu, Companhia Brasileira de Teatro, Nudity, Pact of absence, Literalness.

Há uma afinidade de conduta entre os espetáculos criados pelo dramaturgo e encenador Marcio Abreu com a companhia brasileira de teatro. Essa afinidade é construída por uma ética na lida com o teatro, na forma como o teatro é pensado pelos artistas como algo que está no mundo. Esse pensamento sobre teatro se concretiza nos procedimentos e nas estratégias colocados em prática no processo de criação e nas escolhas da encenação.

Uma das questões que o dramaturgo e diretor costuma apontar sobre o que move seu trabalho é a angústia em relação à escuta. Sua ideia de dramaturgia é pontuada por táticas que procuram desestabilizar o que ele chama de "pacto de ausência". Esse pacto de ausência faz com que nós estejamos 
fisicamente presentes sem estarmos de fato participando do que acontece, sem estarmos disponíveis para uma experiência do momento presente. No teatro, uma situação em que há aparência de convívio pode passar em branco para todas as partes. Esse acordo não dito também é um acordo irrefletido, algo que parece ter se instalado sem o nosso consentimento, sem a nossa percepção. É algo naturalizado. Consideramos "normal" a presença ausente.

Não se trata de um problema específico do teatro. O pacto de ausência é algo do mundo, que infecta o teatro como todas as coisas. Há quem diga que esse é um problema de hoje em dia, da internet, do telefone celular etc., que antigamente as coisas não eram assim. Não sabemos se um dia houve de fato um teatro de perfeita comunhão de presenças em uma era de ouro perdida. Mas o teatro parece estar sempre trabalhando para recuperar perdas. Estamos sempre atrás de algo além, anterior, maior, mais profundo. No caso das peças de Marcio Abreu, é possível perceber gestos que querem desnaturalizar apatias, ardis que trabalham na contramão da banalização.

É importante observar que dramaturgia e encenação constituem instâncias praticamente indiscerníveis nas suas criações. A separação de texto e cena não dá conta da divisão. Por isso vamos chamar essa ação combinada de "escritura cênica", às vezes apenas "escritura". O repertório da companhia é composto de montagens de textos previamente escritos, criados em outros contextos culturais, e de criações próprias, como Vida e PROJETO bRASIL. É preciso atentar para o fato de que as operações de leitura e tradução são criativas, demandam intervenção autoral. Assim, mesmo as peças traduzidas contam com uma dramaturgia que não está dada no texto, que vem com o gesto de escolher a peça, de encená-la de determinada maneira, às vezes com a necessidade de reescrevê-la para ser fiel a sua poética. Podemos pensar que tradução, dramaturgia e encenação constituem um mesmo movimento de escrita da cena, que é autoral sem reivindicação de originalidade.

O trabalho sobre a escuta pode ser em parte mais facilmente identificado no texto, na medida em que se pode perceber estratégias no uso das palavras, construções de frases e diálogos que explicitam um endereçamento ao espectador. Mas há uma dimensão da escritura cênica que convida a um tipo de escuta que se dá no corpo. Parece que o uso do termo "escuta " é uma metonímia. O pacto de ausência também é um pacto de anestesia, de 
alienação. A escuta é uma sensibilidade, uma escuta que também é do corpo, uma sensação de presença do espectador.

"Presença" é uma palavra desgastada do vocabulário do teatro, muito usada quando se fala sobre o trabalho de atuação. Mas a proposta aqui é pensar sobre a sensação de presença do espectador - a quebra do pacto de ausência. Essa sensação de presença acontece quando o espectador é fisgado, quando ele se dá conta de que não está indiferente àquela situação, que ele está implicado.

Para conquistar essa relação, os procedimentos de cena não podem ser "aplicados" como mero truque, como artifício barato, irrefletido. Entendemos por truque aquilo que atua na lógica da espetacularização. Impressionar o espectador ou surpreender o espectador apenas dá continuidade à apatia camuflada de diversão.

O trabalho a que nos referimos é uma operação crítica, uma escolha consciente, precisa, elaborada. Para desestabilizar o que está naturalizado, uma das estratégias das peças de Marcio Abreu é o trabalho sobre a nudez. Mas como pode a nudez atuar sobre a escuta? Como pode a artificialidade do nu desnaturalizar a desatenção? "Artificialidade" é uma palavra-chave. A nudez no teatro em questão não é uma nudez "natural." Nada nas encenações de Marcio Abreu é ou quer ter a aparência de ser natural.

A sofisticação do trabalho sobre o nu aparece especialmente em algumas peças, como Descartes com lentes, Isso te interessa?, PROJETO bRA$S I L$ - peças da companhia brasileira de teatro - e na peça mais recente do grupo Galpão, Nós. Não faremos aqui uma análise detalhada de cada obra, apenas apontamentos - intuitivos, tateantes, empíricos - sobre o tratamento dado aos corpos nus nessas peças.

Em todas elas, a escritura cênica expõe os seus procedimentos, sua construção, como nas frases escritas no cenário de Descartes com lentes; na descrição falada dos movimentos de cena e dos estados em que os personagens se encontram em Isso te interessa?; na dublagem em PROJETO bRASIL; na repetição de diálogos e estruturas em Nós. A nudez também é uma construção. Para estar nu, em cena, nas basta não vestir um figurino. É uma operação de redução, uma depuração. Não se trata de uma transposição neutra do corpo cotidiano para a cena. $\mathrm{O}$ corpo do ator é um procedimento 
do teatro, não é uma coisa dada. A nudez em cena é artificial porque é trabaIhada, cercada de enquadramentos, tempos, narrativas, imagens e palavras.

Por um lado, há a dimensão de realidade da nudez. Cada nudez tem a sua inscrição. O corpo, em cena, é uma superfície plástica de inscrição do real. Essa dimensão de realidade pode atuar sobre a percepção do espectador. A concretude da presença do corpo do outro pode despertar a consciência da concretude do próprio corpo e, por consequência, da própria presença. Essa é, de fato, uma questão do teatro, da dimensão convivial do teatro, anterior a qualquer poética. Mas até a dimensão convivial é naturalizada a ponto de ser ignorada, como já dissemos. Percebemos a presença ausente quando nos damos conta de que algumas pessoas se comportam na plateia como se houvesse uma separação espaço-temporal entre cena e espectador - e até mesmo entre espectadores, apesar da proximidade.

Pode-se argumentar que a nudez no teatro é muito comum, que todo mundo faz, sempre fez e que não há nada de especial nisso. É importante esclarecer que não estamos falando de "novidade", "inovação" ou outras categorias vazias de valoração, mas de um elemento de cena como outro qualquer. É o tratamento dado a esse elemento que parece fazer a diferença. A linha de corte que tira esses trabalhos do círculo da banalidade é difícil de traçar, porque não é apriorística.

Há um trabalho de elaboração formal sobre a nudez, uma camada de arte formada por tramas: por um lado, o trabalho do ator sobre o seu próprio corpo; por outro, a escritura cênica, a situação inteira exterior ao corpo (e que o inclui). A escritura atua em pelo menos duas camadas: as articulações mais diretamente ligadas ao entendimento, ao intelecto; e a visualidade, a dimensão pictórica, que atua de modo menos discursivo. $\mathrm{O}$ estudo do nu está relacionado ao estudo da beleza nas artes pictóricas, não à mera representação de cenas com nudez. Nas peças da brasileira, Marcio Abreu não lança mão da nudez em cenas de sexo ou em cenas naturalistas em que personagens poderiam estar nus. A nudez em suas peças não é temática, é formal.

Em Descartes com lentes, solo de Nadja Naira a partir do conto de Paulo Leminski, o que se vê é um nu individual, simbólico, o nu feminino - o gênero é uma questão. Há um jogo de ilusão com o corpo da atriz, que a princípio alude a um corpo masculino. O desnudamento pontua a narrativa. 
O texto traz a imagem dos aparelhos óticos, dos artifícios para manipular as possibilidades do olhar. Como o telescópio, o microscópio, as lentes, de modo geral, a escritura também age sobre o olhar. Embora os procedimentos nesse espetáculo sejam simples e despretensiosos, o próprio texto falado e o trabaIho feito com o texto escrito no cenário e no corpo da atriz forjam a construção de um arcabouço para a nudez. O corpo é parte da musicalidade impressa na fala. A nudez é o ponto culminante da narrativa, uma conquista, uma revelação, uma vitória. Há uma ênfase de que o corpo é o material usado para dar a ver aquela narrativa tão verborrágica. A nudez da atriz é superfície de inscrição de ideias, o campo de um deciframento. Como o próprio texto diz, há um embate entre os enganos deleitáveis do corpo e a tentativa racionalizadora da mente. O processo de descobrir o corpo, de revelá-lo, acompanha o processo de decifrar o outro. Assim, a ação da peça acontece no corpo nu.

Em Isso te interessa?, espetáculo criado a partir da peça Bon, Saint Cloud de Noëlle Renaud, a nudez é parte de um investimento no pictórico. $O$ cenário de Fernando Marés apresenta o palco italiano como uma pintura sobre uma tela, marcando as linhas da perspectiva. Esse expediente geométrico enfatiza a abordagem formal de uma narrativa que se poderia tomar como realista. A tridimensionalidade natural do espaço teatral é atravessada por traços que forjariam uma ilusão de tridimensionalidade em uma superfície plana. $O$ espaço da cena é visto por um olhar de arte. A combinação da cenografia com a iluminação de Nadja Naira forma uma paleta de cores na qual os corpos nus se encaixam como numa composição pictórica. O corpo nu se torna cor.

Além dessa dimensão visual, se tomarmos aqueles corpos como elementos de uma narrativa, vemos a nudez cotidiana de todos nós, uma nudez dentro de casa, nudez da vida burguesa. Ali vemos a espécie, que nasce, vive, se reproduz e morre protegida dentro de casa. A raça humana e o cachorro estão sob as mesmas condições de domesticação. Há uma nota de solidão na nudez, porque nenhum corpo é idêntico a outro. A nudez de um corpo é sempre única, individual. Já a nudez de um grupo remete ao corpo biológico, de espécie, que tem traços de hereditariedades, repetições, um corpo animal. Essas dimensões atuam sobre o entendimento da cena e sobre a nossa participação, enquanto espectadores, na história daquela família-síntese da vida de classe média. 
A nudez faz a agulha da percepção oscilar entre a "superfície" da materialidade de uma cena formal, construída, e o "interior" da narrativa, de personagens com subjetividades. $O$ fato de que os atores estão nus parece colaborar para esse ir e vir que traz a atenção sempre de volta ao tempo presente. As tatuagens de Ranieri Gonzales, por exemplo, são como um fator de desestabilização da ficção, mesmo em uma narrativa de ficção: o real está inscrito em sua pele.

Em PROJETO bRASIL, em que o diretor assina a dramaturgia com o elenco formado por Giovana Soar, Nadja Naira e Rodrigo Bolzan, arriscamos dizer que há uma espécie de nudez no tratamento dos textos, como os de Christiane Taubira e José Mujica. Uma nudez trabalhada: não se trata de mera citação, mas de interpolação dos discursos. Na matemática, interpolação é o método que permite construir um novo conjunto de dados a partir de um conjunto discreto de dados pontuais previamente conhecidos. Não é aleatório que Marcio Abreu use uma expressão da matemática para nomear um procedimento formal. Em PROJETO bRASIL há cálculo, desenho, geometria na inclusão de textos, assim como de canções. A introdução ou intercalação de frases em uma dramaturgia é uma operação parecida com a do nu trabalhado. O nu poderia ser mera citação, mas também é interpolação, porque é inserido para a construção de um novo conjunto de dados - não é um apêndice, nem exemplificação, ilustração ou reiteração. Nessa peça, os corpos nus são biológicos, corpos da espécie, mas que são dados ao nosso olhar depois de termos sido impregnados de conteúdos políticos, urbanos, culturais. Assim nos vemos como espécie política, ao mesmo tempo primitiva e urbana nas nossas escolhas. Na cena em que os corpos nus desenvolvem movimentos que remetem a uma representação de primitividade, percebe-se como a nossa noção de primitividade é uma noção cultivada, trabalhada. Não vemos nada sem moldura, sem perspectiva, sem narrativa. Nada é absolutamente nu, natural. Não existe nudez no olhar.

Em Nós, a nudez é mítica. Os corpos nus de Eduardo Moreira e Teuda Bara mostram o corpo afetado pelo mundo, pela natureza e pela ação perversa do homem sobre a natureza. Enquanto em Isso te interessa? os corpos estão resguardados pela casa, em Nós os corpos estão afetados pela lama. Os corpos são o mundo, a terra, a natureza modificada, cultivada, explorada, 
violada. A lama de Mariana, da Samarco, da Vale, já cobriu os nossos corpos. Nós mesmos nos cobrimos com essa lama e nos ajudamos uns aos outros com isso, como fazem os atores.

Tateando esses exemplos, procuramos entender a nudez como operação crítica desestabilizadora da desatenção, do pacto de ausência. Como em nenhum dos casos se trata de uma nudez erotizada, comodificada, nem serve como mera espetacularidade pseudotransgressora, o espectador precisa pensar sobre o que está vendo. Fora do uso banal, a razão de ser da nudez não está dada a priori.

Além do já mencionado pacto de ausência, parece que o teatro também precisa lidar com uma febre de literalidade, uma crença na abordagem literal das coisas, um entendimento ao pé da letra, em que não há complexidade possível. Uma coisa está atrelada à outra. A pobreza de conhecimento é consequência da pobreza da experiência. É possível identificar no teatro feito por Marcio Abreu não só uma chamada à presença, à atenção e à escuta, mas uma chamada à elaboração. Entre o olho e a cena, há trabalho - feito $\mathrm{e}$ a fazer. $O$ teatro está aí para nos mostrar que não existe matéria bruta e não existe olho puro. $\mathrm{O}$ espectador precisa ter consciência das mediações e tomar posse das mediações. O que é imediato não serve para a lida com as obras do mesmo modo que não serve para a lida com o mundo.

A crença na legitimidade da reação imediata, da opinião irrefletida, da sensação do momento como experiência da verdade é uma forma de apatia - por mais que possa ser carregada de intensidades. $O$ hábito de não se demorar sobre as coisas, de não enfrentar uma complexidade, de não se deixar implicar, é sintoma da naturalização da indiferença: um problema a enfrentar.

A nudez que não é natural, temática, ilustrativa, gera desconfiança dos assuntos, dos temas. A nudez formal, artificial, é uma coisa da arte, que nunca é natural. $\mathrm{O}$ convite à complexidade é um lugar de resistência do teatro, uma ética que inscreve o teatro no mundo, numa relação de responsabilidade com as coisas do mundo. A nudez do outro convoca o corpo à consciência de si, à presença na experiência. Quem sabe a escuta do corpo, o estado do corpo implicado, despertado do torpor da ausência, pode abrir as condições para que se quebre também a tendência à literalidade. 


\section{Referências bibliográficas}

ABREU, M. Roteiro de uma fala. In: SMALL, D. A.; OLIVEIRA, D. de. (Orgs.). $3^{\circ}$ Encontro Questão de Crítica. Rio de Janeiro: 7 Letras, 2016. Disponível em: <http:// www.questaodecritica.com.br/wp-content/uploads/2016/06/3-Encontro-Questa\%CC\%83o-de-Cri\%CC\%81tica-livro.pdf>. Acesso em: 20 nov. 2016.

ABREU, M. Maré/PROJETO bRASIL. Rio de Janeiro: Cobogó, 2016.

LARROSA, J. Notas sobre a experiência e o saber da experiência. Revista Brasileira de Educação, Campinas, n. 19, p. 20-28, jan./abr. 2002.

ROMAGNOLLI, L. A família sob a perspectiva do teatro: crítica do espetáculo Isso te interessa?, da companhia brasileira de teatro. Questão de Crítica, Rio de Janeiro, v. 5, n. 42, mar. 2012. Disponível em: <http://www.questaodecritica.com. br/2012/03/a-familia-sob-a-perspectiva-do-teatro/>. Acesso em: 20 nov. 2016.

SMALL, D. A. Virá?: crítica da peça PROJETO bRASIL da companhia brasileira de teatro. Questão de Crítica, Rio de Janeiro, v. 8, n. 66, dez. 2015. Disponível em: <http://www.questaodecritica.com.br/2015/12/projeto-brasil/>.

SMALL, D. A. Um olhar com pensamento dentro: crítica da peça Descartes com lentes. Questão de Crítica, Rio de Janeiro, v. 3, n. 27, nov. 2010. Disponível em: $<$ http://www.questaodecritica.com.br/2010/11/um-olhar-com-pensamento-dentro/>. Acesso em: 20 nov. 2016.

SMALL, D. A. Exposição e partilha da condição humana. Cena Contemporânea, Brasília, 26 ago. 2015. Disponível em: <http://www.cenacontemporanea.com.br/ exposicao-e-partilha-da-condicao-humana/>. Acesso em: 20 nov. 2016.

Recebido em 24/09/2016

Aprovado em 28/10/2016

Publicado em 21/12/2016 